\title{
Editorial
}

\section{Planning for Sustainable Cities and Communities}

In an era where a great majority of the world population is progressively embracing the urban way of life, finding more effective means of serving the ever-increasing needs of the cities and their inhabitants is not a choice, but a necessity for all professionals including planners. 'Cities and Communities' are placed in the $11^{\text {th }}$ in the list of 17 Sustainable Development Goals, which all UN member nations strive to accomplish by 2030. Accomplishment of sustainable cities and communities requires genuine efforts of planners and policy makers to strategize the current state of affairs of human settlements in many fronts, including physical environments and their functional order, socio-economic aspirations and deep socio-psychological needs of their communities.

This issue of Bhumi provides readers with four interesting papers from four such different subjects related to the planning and designing of safe, comfortable and sustainable human settlements and happy, peaceful and healthy communities.

No resident would be psychologically comfortable when the tenure of the place of their shelter is not secured with some formality. In the modern age, in almost all countries, land or property deeds are the widely practiced means of security for those who possess and occupy them, and the deeds are legitimized by registering them in a ledger in a government secretariat. Yet, this method could not address the complications arising from the myriad of information bundled with land parcels. Hence, many countries have already replaced the age-old deed registration with more informative title registration systems. A similar project has been implemented in a few districts of Sri Lanka. Even though the project is progressing smoothly, the expected transformation seems delayed due to many factors. The first paper presented herein brings in some findings as to what matters for people to feel secured about their property with the new land title registration process. Through converging analysis of the findings of a limited, but in-depth survey carried out on the said project in Sri Lanka, it concludes that the awareness and participation of the title holders, the trustworthiness and the credibility of the information system, and the attitudes of the people were the factors on which the successful implementation of the overall land title registration varied.

Road safety is a prime concern for the livability of cities and other forms of human habitats nowadays because of the increased mobility of individuals as well as the overwhelming use of automobile. A safe and well-maintained public road network is an integrated component of accessibility while road traffic accidents indicate the level of safety in a public road network. The second paper presented in this issue identified eighteen causes of road traffic related accidents, most of which are internal to the riders of the automobile. Law enforcement by the authorities as well as the self-discipline of drivers are highlighted, not undermining the safe design standards of road infrastructure. Through a limited, but 
carefully designed qualitative inquiry, the paper also suggests nineteen strategies that can enhance road safety and thereby contribute to improve the liveability of human settlements. Green spaces contribute a lot towards sustainable cities and communities, especially in residential zones of contemporary urban areas. In situations where public open spaces are scarce, privately owned green spaces provide individual families and smaller communities with space for needy leisure, recreation and socializing opportunities. Private gardens also provide many families with a variety of sources of household income through measures such as agriculture, horticulture, dairy farming, etc. Out of a study in the city of Galle and its surrounding suburban area in the Southern coast of Sri Lanka, the third paper observed the limited utility of private garden spaces despite the numerous potentials that they provided. In a situation where the local governments or other authorities do not have the possibility and the capacity to provide adequate green open spaces for its residents, either due to scarcity or the costs of lands, the private garden spaces, both individually and collectively, can partially fulfill this requirement by acting as carbon sinks, green lungs, facilitating for biodiversity and gifting pleasant environments.

Community involvement in decisions in development projects from their planning and design stages is often advocated as an effective strategy towards building sustainable cities and neighbourhoods. This is more so in housing development projects, where the main stakeholders are the long-term occupiers. Sharing true information sincerely, purposefully and with all relevant parties, at the correct moment and in the appropriate communicative manner is the key for effective engagement of stakeholders. The last paper, on the 'communicative planning potentials of housing estate development process', though based on a case in England, provide valuable insights which can be generalized into many communities. Founded on the essence of Jurgen Habermas's theory on communicative action, 'communicative planning' has been rhetoric in planning circles and academic discourse, but yet to be seen widely practiced to its full potential, except for a few cases found around the world. The case of Dickens Heath New Settlement (DHNS) - a large scale housing estate development in the West Midlands of England, studied by the paper reveals that communicative planning had a negligible impact at the conceptual planning stage, but accrued relatively positive outcomes at the design, development and management phases of estate development. The study highlights the positive impacts of communicative planning at the post occupation stage of a housing estate, which are increasingly becoming popular in and around cities in many countries, including Sri Lanka.

The four subject matters of the four papers are timely and relevant in all terms, and hopefully will enlighten our readers. More importantly, they serve the continuous effort of Bhumi to expand the scope and depth of knowledge in academics and practitioners in planning and the allied disciplines.

\section{Prof. Jagath Munasinghe}

\section{Editor-in-Chief}

